\title{
Prognostic implications of type and density of tumour-infiltrating lymphocytes in gastric cancer
}

\author{
HE Lee', SW Chae', YJ Lee ${ }^{3}$, MA Kim ${ }^{3}$, HS Lee', BL Lee ${ }^{4}$ and WH Kim ${ }^{* 3,4}$ \\ 'Department of Pathology, Seoul National University Bundang Hospital, Seongnam, Korea; ${ }^{2}$ Department of Pathology, Kangbuk Samsung Hospital, \\ Sungkyunkwan University School of Medicine, Seoul, Korea; ${ }^{3}$ Department of Pathology, Seoul National University College of Medicine, Seoul, Korea; \\ ${ }^{4}$ Cancer Research Institute, Seoul National University College of Medicine, Seoul, Korea
}

The study aims to determine whether type and density of tumour-infiltrating lymphocytes (TILs) can predict the clinical course in gastric cancer. Gastric carcinomas $(n=220)$ were immunostained for CD3, CD8, CD20, and CD45RO and evaluated for clinicopathologic characteristics. Number of TILs that immunostained positively for each marker were counted using $\mathrm{NIH} \mathrm{ImageJ}$ software. Tumours were grouped into low- and high-density groups for each marker (CD3, CD8, CD45RO). The densities of $\mathrm{CD}^{+}, \mathrm{CD}^{+}$, and $\mathrm{CD} 45 \mathrm{RO}{ }^{+}$TILs were found to be independent predictors of lymph node metastasis by multivariate analysis with odds ratios $(95 \% \mathrm{Cl}$ ) of 0.425 (0.204-0.885), 0.325 (0.150-0.707), and 0.402 (0.190-0.850), respectively. Kaplan-Meier survival analysis revealed that patients in the high-density groups for CD3, CD8, and C45RO had a significantly longer survival time than the patients in the corresponding low-density groups, respectively. In multivariate survival analysis, the densities of CD3 ${ }^{+}$, $\mathrm{CD}^{+}$, and $\mathrm{CD} 45 \mathrm{RO}{ }^{+}$TILs remained independent prognostic factors with hazard ratios (95\% Cl) of 0.549 (0.3 I7-0.95I), 0.574 (0.347-0.949), and $0.507(0.298-0.862)$, respectively. In conclusion, density of TILs was found to be independently predictive of regional lymph node metastasis and patient survival in gastric cancer.

British Journal of Cancer (2008) 99, |704- |7|I. doi:I0.1038/sj.bjc.6604738 www.bjcancer.com

Published online 21 October 2008

(c) 2008 Cancer Research UK

Keywords: stomach neoplasms; tumour-infiltrating lymphocyte; immunohistochemistry; survival analysis; tissue array analysis

\begin{abstract}
Despite a decreasing trend in its incidence, gastric cancer remains one of the most frequent causes of cancer-related death worldwide; more than 930000 new cases are diagnosed and 700000 deaths occur each year (Parkin et al, 2005). At present, surgical resection is considered the most reasonable procedure (Engstrom et al, 1985; Coombes et al, 1990), and tumour-node-metastasis (TNM) stage (by UICC/AJCC) assessed after resection is viewed as the prognostic factor that is most strongly associated with patient survival. However, it is not rare that gastric cancer patients with the same TNM stage pursue different clinical courses. Histopathologic classifications including WHO classification (FenoglioPreiser et al, 2000), Lauren's classification (Lauren, 1965), Ming's classification (Ming, 1977), and Goseki classification (Goseki et al, 1992) and molecular classifications (Hippo et al, 2002; Chen et al, 2005) have also been applied for the prediction of patient survival, but their prognostic accuracies are controversial (Lewin and Appleman, 1996; Fenoglio-Preiser et al, 2000). In addition, many attempts have been made to link molecular events in cancer cells with patient outcome, but none of these have been accepted to be clinically meaningful. In consequence, new prognostic
\end{abstract}

\footnotetext{
*Correspondence: WH Kim, Department of Pathology, Seoul National University College of Medicine, 28 Yongon-dong, Seoul I I 0-799, Korea; E-mail:woohokim@snu.ac.kr

Received 24 June 2008; revised 23 September 2008; accepted 24 September 2008; published online 21 October 2008
}

determinants in conjunction with the TNM stage are required to predict patients' clinical course more reliably and precisely.

As the cancer immunosurveillance hypothesis was first proposed, the concept that the immune system can recognise and eliminate tumour cells has been energetically debated. Many experimental rodent studies on transgenic and knockout mice, and on monoclonal antibodies specific for distinct immunologic components have provided substantial evidence for the existence of cancer immunosurveillance, and in particular, have shown that the immune system indeed functions to protect murine hosts against development of both chemically induced and spontaneous tumours (Dunn et al, 2004). Moreover, in humans, epidemiologic data indicate that immunocompromised patients have a higher probability of developing cancers of both viral and non-viral origin, which supports the cancer immunosurveillance concept (Dunn et al, 2004). In addition, an accumulating evidence shows a positive correlation between the presence of lymphocytes in tumour tissue and increased patient survival.

Recent studies have shown that several types of tumourinfiltrating lymphocytes (TIL) are associated with better disease outcome for various human cancers, including melanoma (Clemente et al, 1996; Taylor et al, 2007) and colorectal (Pages et al, 2005; Galon et al, 2006), ovarian (Zhang et al, 2003), cervical (Piersma et al, 2007), hepatocellular (Gao et al, 2007), and urothelial (Sharma et al, 2007) carcinoma. These reports demonstrate that high numbers of $\mathrm{CD}^{+}, \mathrm{CD}^{+}$, or $\mathrm{CD} 45 \mathrm{RO}^{+}$ $\mathrm{T}$ cells in tumour tissue are significantly correlated with lower frequencies of lymph node metastasis or disease recurrence, or 
longer patient survival. Moreover, Galon et al (2006) advocated that the type, density, and location of immune cells in colorectal cancer have prognostic values that are superior to and independent of those of the TNM classification. However, the effect of TILs on the clinical course of gastric cancer patients is largely unknown.

The aim of this study was to assess the prognostic role of TILs in gastric cancer. Here, we determined whether type and density of TILs can predict the regional lymph node metastasis and patient survival in gastric cancer.

\section{MATERIALS AND METHODS}

\section{Patients and specimens}

The files of 274 surgically resected consecutive gastric carcinoma cases examined at the Department of Pathology, Seoul National University Hospital between January and June 1995 were obtained to quantify TILs by immunohistochemistry using a tissue array method. Cases with cancer confined to mucosa were excluded because they have an excellent prognosis regardless of TIL status. Finally 220 tumour tissue samples were included in the analysis. Age, sex, histologic type (according to Lauren and WHO classifications), lymphatic invasion, and pTNM (pathologic TNM) stage were evaluated by reviewing medical records or the glass slides. Patient clinical outcomes were followed from the date of surgery until either the date of death or 31 December 2003, which resulted in a follow-up period that ranged from 1 to 108 months (mean, 64.4 months). The data of patients lost to follow-up and of those who died from a cause other than gastric cancer were regarded as censored during the survival analysis. No patient had received preoperative chemotherapy, and patients with stage II, III, and IV had received postoperative chemotherapy using fluorouracil (5-FU) -based regimen (5-FU alone, 5-FU plus mitomycin $\mathrm{C}$, or 5-FU plus cisplatin). No patient had received pre or postoperative radiotherapy. This study was approved by the Institutional Review Board for Human Subject Research at Seoul National University Hospital.

\section{Tissue array method}

Core tissue biopsies ( $2 \mathrm{~mm}$ in diameter) were taken from individual paraffin-embedded gastric carcinomas (donor blocks) and re-arranged in a new recipient paraffin block (tissue array block) using a trephine apparatus (Superbiochips Laboratories, Seoul, Korea). Six array blocks containing a total of 274 cases were prepared. As it has been shown that excellent staining result agreements are obtained for different intratumoral areas of gastric carcinomas (Lee et $a l, 2001$ ), a core was sampled from each of the cases. Each paraffin block contained internal controls consisting of non-neoplastic gastric mucosa from the body, antrum, and intestinal metaplasia. Sections $(4 \mu \mathrm{m})$ were taken from each tissue array block, deparaffinised, and dehydrated.

\section{Immunohistochemistry}

Formalin-fixed and paraffin-embedded sections were dewaxed in xylene, rehydrated through graded alcohol, and placed in an endogenous peroxide block for $15 \mathrm{~min}$. Antigen retrieval was done using a microwave in $10 \mathrm{~mm}$ citrate buffer or using an autoclave in Borg solution (Biocare Medical, Walnut Creek, CA, USA). Nonspecific staining was blocked by treating sections with $1 \%$ horse serum in Tris-buffered saline $(\mathrm{pH} 6.0)$ for $3 \mathrm{~min}$. Anti-CD3 (total T-cell marker; microwave; 1:100; rabbit polyclonal; DAKO, Glostrup, Denmark), -CD8 (cytotoxic T-cell marker; autoclave in Borg solution; 1:100; Rabbit monoclonal, SP16; Neomarkers, Fremont, CA, USA), -CD20 (total B cell marker; microwave; $1: 300$; Mouse monoclonal, L26; DAKO), and -CD45RO (memory
T-cell marker; microwave; 1:100; Mouse monoclonal, OPD4; Neomarkers) antibodies were then applied, and antibody binding was detected using an avidin-biotin-peroxidase complex (Universal Elite ABC Kit; Vectastain, Burlingame, CA, USA) for 10 min. Diaminobenzidine tetrahydrochloride solution (Kit HK1535K; Biogenex, San Ramon, CA, USA) was then used as a chromogen.

\section{Quantitative analysis of TILs}

Immunostained slides were scanned with a digital virtual microscope (dotSlide, Olympus, Hamburg, Germany), and a portion (area of $0.44 \mathrm{~mm}^{2}$ of tumour centre) of the virtual images was captured using an image viewer programme (OlyVIA, downloaded from http://www.olysia.co.kr/olyvia2992.zip) per case. The captured images were $1263 \times 932$ pixel in size and had a resolution of 1.633 pixel $\mu \mathrm{m}^{-1}$ at a magnification of $\times 100$. Numbers of positively immunostained cells per in the $0.44 \mathrm{~mm}^{2}$ target areas were counted using NIH imageJ software with a Javabased colour deconvolution plugin (http://rsb.info.nih.gov/ij).

\section{Statistical analysis}

Comparisons between groups were performed using the Pearson's $\chi^{2}$ test or Fisher's exact (2-sided) test. Multivariate logistic regression was used to identify clinical and pathologic features predictive of regional lymph node metastases. Survival curves were estimated using the Kaplan-Meier product-limit method, and the significances of differences between survival curves were determined using the log-rank test. Multivariate comparisons of survival distributions were made using Cox proportional hazards models. All statistical analyses were conducted using SPSS 15.0 (SPSS, Chicago, IL, USA), and $P$-values of $\leqslant 0.05$ were considered statistically significant.

\section{Two-fold cross-validation approach}

To dichotomise prognostic variables, CD3, CD8, and CD45RO, a two-fold cross-validation methodology and a minimum $P$-value approach (Mazumdar et al, 2003) were used. The dataset was randomly divided into two subsets. The inner $70 \%$ of the distribution from a marker was chosen as a selection interval of an optimal cutoff value. Stratified univariate and multivariate tests (logistic regression and Cox proportional hazards model) were performed for significance of prognostic variables.

\section{RESULTS}

\section{Density of TILs}

Tumour-infiltrating lymphocytes were detected within cancer epithelium or in stroma except for $\mathrm{CD} 20^{+}$TILs, which were mostly present in stroma (Figure 1). Mean numbers of $\mathrm{CD}^{+}$, $\mathrm{CD}^{+}, \mathrm{CD}^{+} 5 \mathrm{RO}^{+}$, and $\mathrm{CD} 20^{+}$TILs per area of $0.44 \mathrm{~mm}^{2}$ were $353.87 \pm 381.55,191.72 \pm 265.69,76.13 \pm 138.30$, and $89.42 \pm 152.45$, respectively. Numbers of $\mathrm{CD}^{+}, \mathrm{CD}^{+}$, and CD45RO ${ }^{+}$TILs were correlated with each other (range of correlation coefficients, $0.739-0.868 ; P<0.001)$, and numbers of $\mathrm{CD} 20^{+}$TIL were positively correlated with those of other TIL subtypes, but correlation coefficients were relatively low (range, 0.527-0.641; $P<0.001)$. First, using mean number, all cases were classified into low- and high-density groups for each marker, that is, $C D 3_{L}, C D 8_{L}$, and $\mathrm{CD} 4 \mathrm{RO}_{\mathrm{L}}$ (low-density groups) and $\mathrm{CD} 3_{\mathrm{H}}, \mathrm{CD} 8_{\mathrm{H}}$, and $\mathrm{CD} 4 \mathrm{RO}_{\mathrm{H}}$ (high-density groups) (Table 1). Also, each 75th percentile in the distributions of the TIL numbers in ascending order were determined as cutoffs (75th percentile cutoffs) for dichotomisation of the variables, that is, 75th percentile or a 

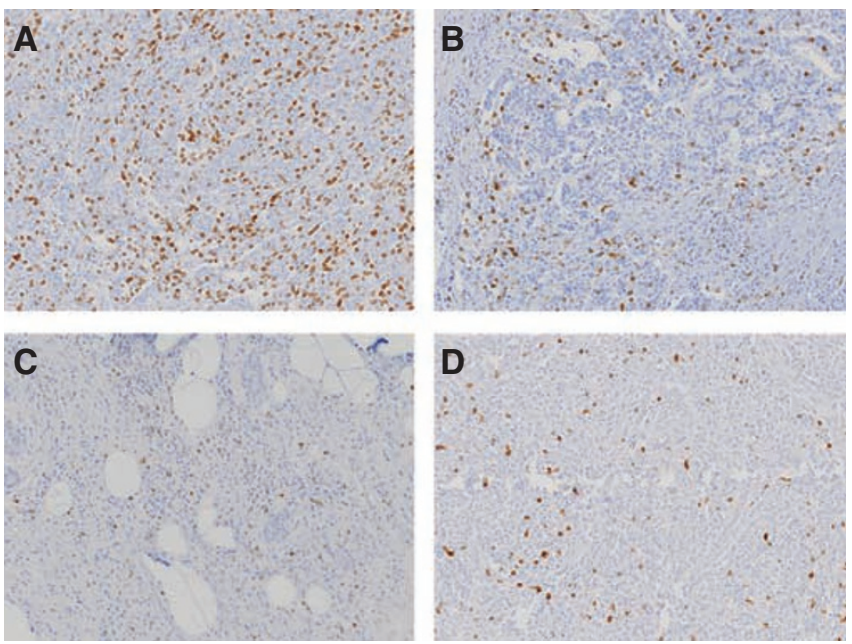

Figure I Types of tumour-infiltrating lymphocytes. CD3 (A), CD8 (B) CD45RO (C), and CD20 (D) expressing cells were detected immunohistochemically. They are tumour-infiltrating total T cells, cytotoxic T cells, memory $T$ cells, and B cells, respectively (original magnification, $\times 100$ ).

Table I Classification of the gastric cancers according to TIL density

\begin{tabular}{|c|c|c|}
\hline Variables & $\begin{array}{c}\text { Mean value } \\
\text { cutoff } \\
\text { (cases, } N \text { ) }\end{array}$ & $\begin{array}{l}\text { 75th percentile } \\
\text { cutoff } \\
\text { (cases, } N \text { ) }\end{array}$ \\
\hline $\begin{array}{l}\mathrm{CD} 3_{\mathrm{L}} / \mathrm{CD} 3_{\mathrm{H}} \\
\mathrm{CD} 8_{\mathrm{L}} / \mathrm{CD} 8_{\mathrm{H}} \\
\mathrm{CD} 45 \mathrm{RO}_{\mathrm{L}} / \mathrm{CD} 45 \mathrm{RO}_{\mathrm{H}}\end{array}$ & $\begin{array}{l}142 / 78 \\
164 / 56 \\
155 / 65\end{array}$ & $\begin{array}{l}165 / 55 \\
164 / 56 \\
165 / 55\end{array}$ \\
\hline $\begin{array}{l}\text { Combination of variables } \\
\text { CD } 3_{L} C D 8_{L} / C D 3 C D 8_{H e t} / C D 3_{H} C D 8_{H} \\
C D 3_{L} C D 45 R O_{L} / C D 3 C D 45 O_{H e t} / \\
C D 3_{H} C D 45 R O_{H} \\
C D 8_{L} C D 45 R O_{L} / C D 8 C D 45 O_{H e t} / \\
C D 8_{H} C D 45 R O_{H} \\
C D 3_{L} C D 8_{L} C D 45 R O_{L} / \\
C D 3 C D 8 C D 45 R O_{H e t} / \\
C D 3_{H} C D 8_{H} C D 45 R O_{H}\end{array}$ & $\begin{array}{l}\mid 35 / 36 / 49 \\
|3| / 35 / 54 \\
|40 / 39 / 4| \\
125 / 55 / 40\end{array}$ & $\begin{array}{l}|50 / 29 / 4| \\
\mid 48 / 34 / 38 \\
146 / 37 / 37 \\
138 / 50 / 32\end{array}$ \\
\hline
\end{tabular}

$\mathrm{H}=$ high density group; Het = mixture of low and high density group for different markers; $L=$ low density group.

percentile less than 75 were considered as low-density groups and a percentile greater than 75 as high-density groups for each marker. Each 75th percentile was 452,191 , and 92 per area of $0.44 \mathrm{~mm}^{2}$, for $\mathrm{CD}^{+}, \mathrm{CD}^{+}$, and CD45RO ${ }^{+}$TILs, respectively. We also grouped cases using combined variables, that is, as high or low for $\mathrm{CD} 3+\mathrm{CD} 8, \mathrm{CD} 3+\mathrm{CD} 45 \mathrm{RO}, \mathrm{CD} 8+\mathrm{CD} 45 \mathrm{RO}$, and $\mathrm{CD} 3+\mathrm{CD} 8+\mathrm{CD} 45 \mathrm{RO}$ (refer to Table 1 for a complete list). We then compared groups dichotomised about means and about 75th percentile cutoffs. Because comparisons of the highand low-density groups of CD20 ${ }^{+}$, TIL using various cutoffs failed to show any significant difference in terms of clinicopathologic characteristics or survival, no detailed data on CD20 $0^{+}$TIL is presented.

\section{Correlation between TIL density and clinicopathologic characteristics}

In a total of 220 gastric cancer patients, median age was 57 years (range, 18-80 years), and 70.9\%. were male. The clinical and pathological characteristics of the cases grouped by TIL density with mean value cutoffs are summarised in Table 2. TIL density showed no correlation with either tumour invasion depth or the presence of lymphatic invasion, but it was found to be significantly associated with the presence of regional lymph node metastasis; $\mathrm{CD} 3_{\mathrm{H}}, \mathrm{CD} 8_{\mathrm{H}}$, and $\mathrm{CD} 45 \mathrm{RO}_{\mathrm{H}}$ groups showed a lower frequency of lymph node metastasis than the corresponding low-density groups. Considering this observation, we assumed that TIL density would predict lymph node metastasis in gastric cancer.

\section{TIL as a predictor of regional lymph node metastasis}

According to univariate logistic regression model, an advanced $\mathrm{T}$ stage, the presence of lymphatic invasion, and low densities of $\mathrm{CD}^{+}, \mathrm{CD}^{+}$, or $\mathrm{CD}_{45 \mathrm{RO}^{+}}$TILs were significantly associated with presence of regional lymph node metastasis regardless of the grouping method (mean value cutoff or 75th percentile cutoff). Low-density groups by combination of variables also showed significant relationships with the presence of lymph node metastasis. Multivariate logistic regression analysis, after adjusting for tumour invasion ( $\mathrm{T}$ stage) and lymphatic invasion, demonstrated that densities of $\mathrm{CD}^{+}, \mathrm{CD}^{+}$, and $\mathrm{CD}^{+} 5 \mathrm{RO}^{+}$TILs were independent predictors of lymph node metastasis. As expected, combined analysis of variables showed similar results (Tables 3 and 4).

\section{TIL as a predictor of patient survival}

Significant advantages for overall survival were found for the $\mathrm{CD} 3_{\mathrm{H}}, \mathrm{CD} 8_{\mathrm{H}}$, and $\mathrm{CD} 45 \mathrm{RO}_{\mathrm{H}}$ groups and for the high-density groups of combined TIL variables (refer to Table 1) according to 75th percentile cutoffs by Kaplan-Meier survival analysis (Figure 2). The analysis with variables according to mean value cutoffs showed similar results (data not shown). $\mathrm{CD} 3_{\mathrm{H}}, \mathrm{CD} 8_{\mathrm{H}}$, and $\mathrm{CD}^{2} 5 \mathrm{RO}_{\mathrm{H}}$ groups had mean survival times of $85.1 \pm 5.2,81.0 \pm 5.3$, and $83.1 \pm 5.3$ months, respectively, as compared with only $63.0 \pm 3.5,64.3 \pm 3.5$, and $63.7 \pm 3.5$ months in the corresponding low-density groups. Thus, the density of various TILs seems to be useful for defining a subgroup with unfavourable prognosis in gastric cancer.

Univariate Cox regression analysis for the prediction of overall survival also confirmed that the $\mathrm{CD}_{\mathrm{H}}, \mathrm{CD} 8_{\mathrm{H}}$, and $\mathrm{CD} 45 \mathrm{RO}_{\mathrm{H}}$ groups and the high-density groups of combined TIL variables had better survival than the corresponding low-density groups regardless of the grouping method (mean value cutoff or 75 th percentile cutoff). In addition, densities of $\mathrm{CD}^{+}, \mathrm{CD}^{+}$and $\mathrm{CD}_{45 \mathrm{RO}^{+}}$TILs and the combined TIL densities remained significant predictors of overall survival by multivariate Cox proportional hazard analysis, even after controlling for $\mathrm{T}$ stage, histologic classification (WHO), presence of lymph node metastasis, and presence of lymphatic invasion, which were all found to be of prognostic significance by univariate analysis (Tables 5 and 6).

\section{Two-fold cross-validation approach}

For further validation of our results, we performed a two-fold cross-validation approach. In analyses using this approach, univariate and multivariate logistic regression analyses confirmed that densities of $\mathrm{CD}^{+}, \mathrm{CD}^{+}$, and $\mathrm{CD}_{4} \mathrm{RO}^{+}$TILs were independent predictors of regional lymph node metastasis (Table 7). In univariate Cox regression analysis, $\mathrm{CD} 3_{\mathrm{H}}, \mathrm{CD} 8_{\mathrm{H}}$, and $\mathrm{CD} 4 \mathrm{RO}_{\mathrm{H}}$ groups were proved to have longer survival time than the corresponding low-density groups (Table 8). In multivariate Cox regression analysis, $\mathrm{CD} 45 \mathrm{RO}^{+}$TIL density remained a statistically significant predictor of overall survival, and CD8 ${ }^{+}$TIL density was associated with overall survival marginally, but $\mathrm{CD} 3^{+}$ TlL density did not remain a significant predictor (Table 8). 
Table 2 Correlation between TIL density and clinicopathologic characteristics in the 220 gastric cancers

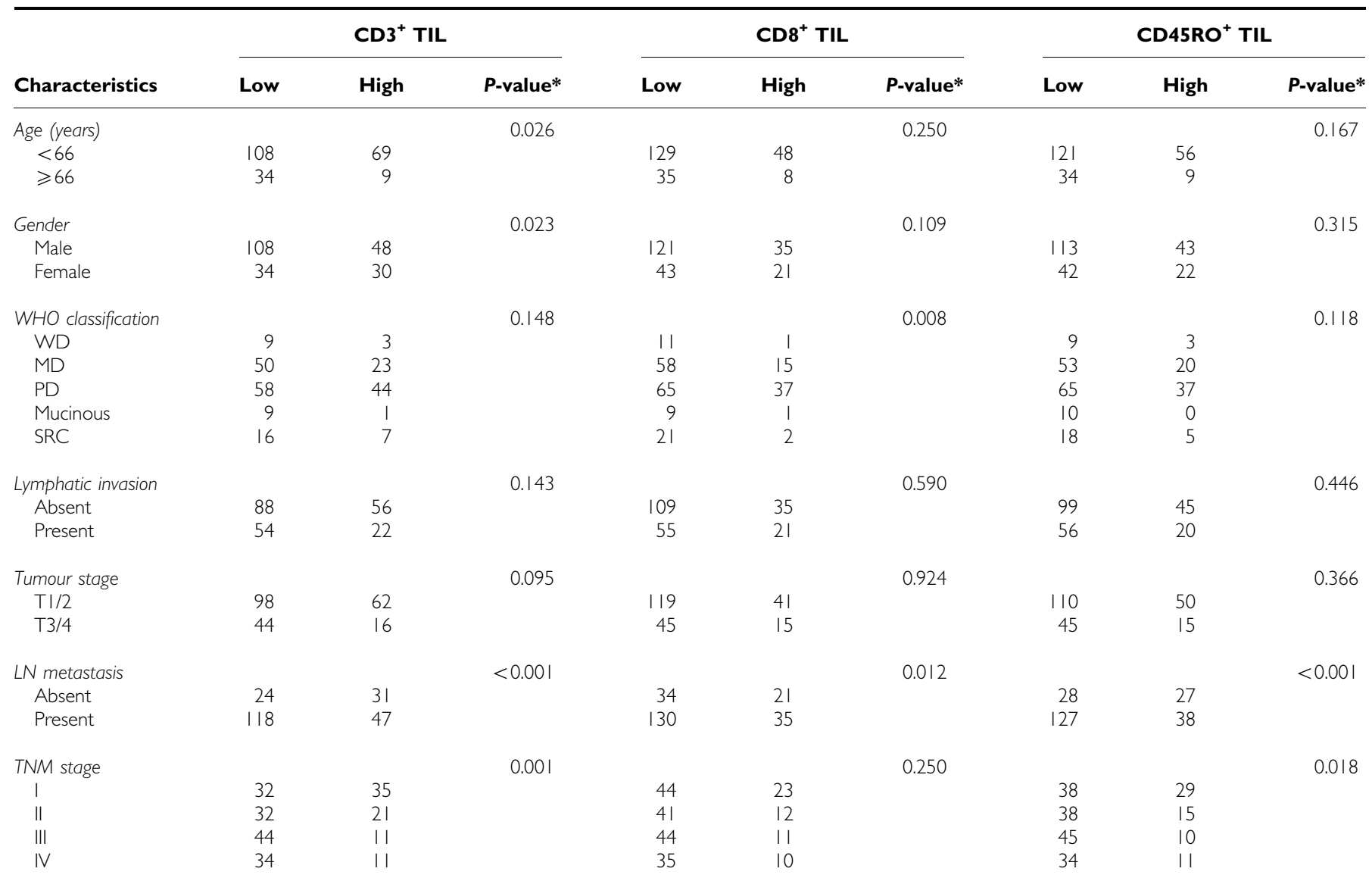

$\mathrm{LN}=$ lymph node; $\mathrm{MD}=$ moderately differentiated tubular adenocarcinoma; Mucinous = mucinous adenocarcinoma; $\mathrm{PD}=$ poorly differentiated tubular adenocarcinoma: $S R C=$ signet-ring cell carcinoma; WD = well differentiated tubular adenocarcinoma. The results were according to the density groups of TIL with mean value cutoffs. * $\chi^{2}$ test was used as a statistical method.

Table 3 Univariate and multivariate logistic regression models for predictors of regional lymph node metastasis (results from mean value cutoffs)

\begin{tabular}{|c|c|c|c|c|c|c|}
\hline \multirow[b]{2}{*}{ Variables } & \multicolumn{3}{|c|}{ Univariate analysis } & \multicolumn{3}{|c|}{ Multivariate analysis $^{\mathbf{a}}$} \\
\hline & OR & $95 \% \mathrm{Cl}$ & $P$-value & OR & $95 \% \mathrm{Cl}$ & $P$-value \\
\hline $\mathrm{CD}^{\mathrm{b}}$ & 0.308 & $0.164-0.580$ & $<0.001$ & 0.350 & $0.175-0.701$ & 0.003 \\
\hline $\mathrm{CD} 8^{\mathrm{b}}$ & 0.436 & $0.225-0.843$ & 0.014 & 0.325 & $0.150-0.707$ & 0.005 \\
\hline CD45RO ${ }^{b}$ & 0.310 & $0.163-0.589$ & $<0.001$ & 0.302 & $0.147-0.622$ & 0.001 \\
\hline CD3CD8 $8^{c}$ & 0.307 & $0.148-0.640$ & 0.002 & 0.277 & $0.122-0.632$ & 0.002 \\
\hline CD3CD45ROc & 0.234 & $0.116-0.473$ & $<0.001$ & 0.236 & $0.107-0.523$ & $<0.001$ \\
\hline $\mathrm{CD}^{8 C D 45 R O^{c}}$ & 0.292 & $0.136-0.625$ & 0.002 & 0.260 & $0.111-0.608$ & 0.002 \\
\hline $\begin{array}{l}\text { CD3CD8 } \\
\text { CD45RO }\end{array}$ & 0.258 & $0.117-0.567$ & 0.001 & 0.257 & $0.108-0.614$ & 0.028 \\
\hline
\end{tabular}

$\mathrm{Cl}=$ confidence interval; $\mathrm{OR}=$ odds ratio. The results were according to the density groups of TIL with mean value cutoffs. Univariate and multivariate logistic regression models were used as statistical methods. ${ }^{\text {TT }}$ umour invasion (T stage) and presence of lymphatic invasion were adopted as covariates in each multivariate analysis. ${ }^{\text {hhigh vs }}$ low. "high/high vs low/low. 'high/high/high vs low/low/low.

\section{DISCUSSION}

The present study demonstrates that the type and density of TILs correlate with the clinical outcome after gastrectomy in gastric cancer. TIL was found to be an independent predictor of lymph node metastasis and an independent prognostic factor of patients'
Table 4 Univariate and multivariate logistic regression models for predictors of regional lymph node metastasis (results from 75 th percentile cutoffs)

\begin{tabular}{|c|c|c|c|c|c|c|}
\hline \multirow[b]{2}{*}{ Variables } & \multicolumn{3}{|c|}{ Univariate analysis } & \multicolumn{3}{|c|}{ Multivariate analysis $^{\mathbf{a}}$} \\
\hline & OR & $95 \% \mathrm{Cl}$ & $P$-value & OR & $95 \% \mathrm{Cl}$ & $P$-value \\
\hline $\mathrm{CD}^{\mathrm{b}}$ & 0.375 & $0.194-0.726$ & 0.004 & 0.425 & $0.204-0.885$ & 0.022 \\
\hline$C D 8^{b}$ & 0.436 & $0.225-0.843$ & 0.014 & 0.325 & $0.150-0.707$ & 0.005 \\
\hline$C D 45 R^{b}$ & 0.420 & $0.217-0.815$ & 0.010 & 0.402 & $0.190-0.850$ & 0.017 \\
\hline $\mathrm{CD} 3 \mathrm{CD}^{\mathrm{c}}$ & 0.338 & $0.161-0.710$ & 0.004 & 0.318 & $0.138-0.734$ & 0.007 \\
\hline $\mathrm{CD}^{\circ} \mathrm{CD} 45 \mathrm{RO}^{\mathrm{C}}$ & 0.321 & $0.149-0.689$ & 0.004 & 0.337 & $0.143-0.793$ & 0.013 \\
\hline $\mathrm{CD} 8 \mathrm{CD} 45 \mathrm{RO}^{\mathrm{c}}$ & 0.400 & $0.180-0.888$ & 0.024 & 0.354 & $0.146-0.860$ & 0.022 \\
\hline $\begin{array}{l}\text { CD3CD8 } \\
\text { CD45RO }^{d}\end{array}$ & 0.369 & $0.160-0.851$ & 0.019 & 0.397 & $0.160-0.988$ & 0.047 \\
\hline
\end{tabular}

$\mathrm{Cl}=$ confidence interval; $\mathrm{OR}=$ odds ratio. The results were according to the density groups of TIL with 75th percentile cutoffs. Univariate and multivariate logistic regression models were used as statistical methods. ${ }^{\text {TT }}$ Tumour invasion (T stage) and presence of lymphatic invasion were adopted as covariates in each multivariate analysis. ${ }^{b} H i g h$ vs low. ${ }^{C H}$ igh/high vs low/low. ${ }^{d} H$ igh/high/high vs low/low/low.

overall survival by multivariate analyses. In addition, we evaluated an effect of TIL density on survival at each stage of TNM classification. Overall survival of patients with a high TIL density tended to be longer than that of patients with a low TIL density within the same TNM stage, although differences were not statistically significant due to small numbers of cases enrolled in 

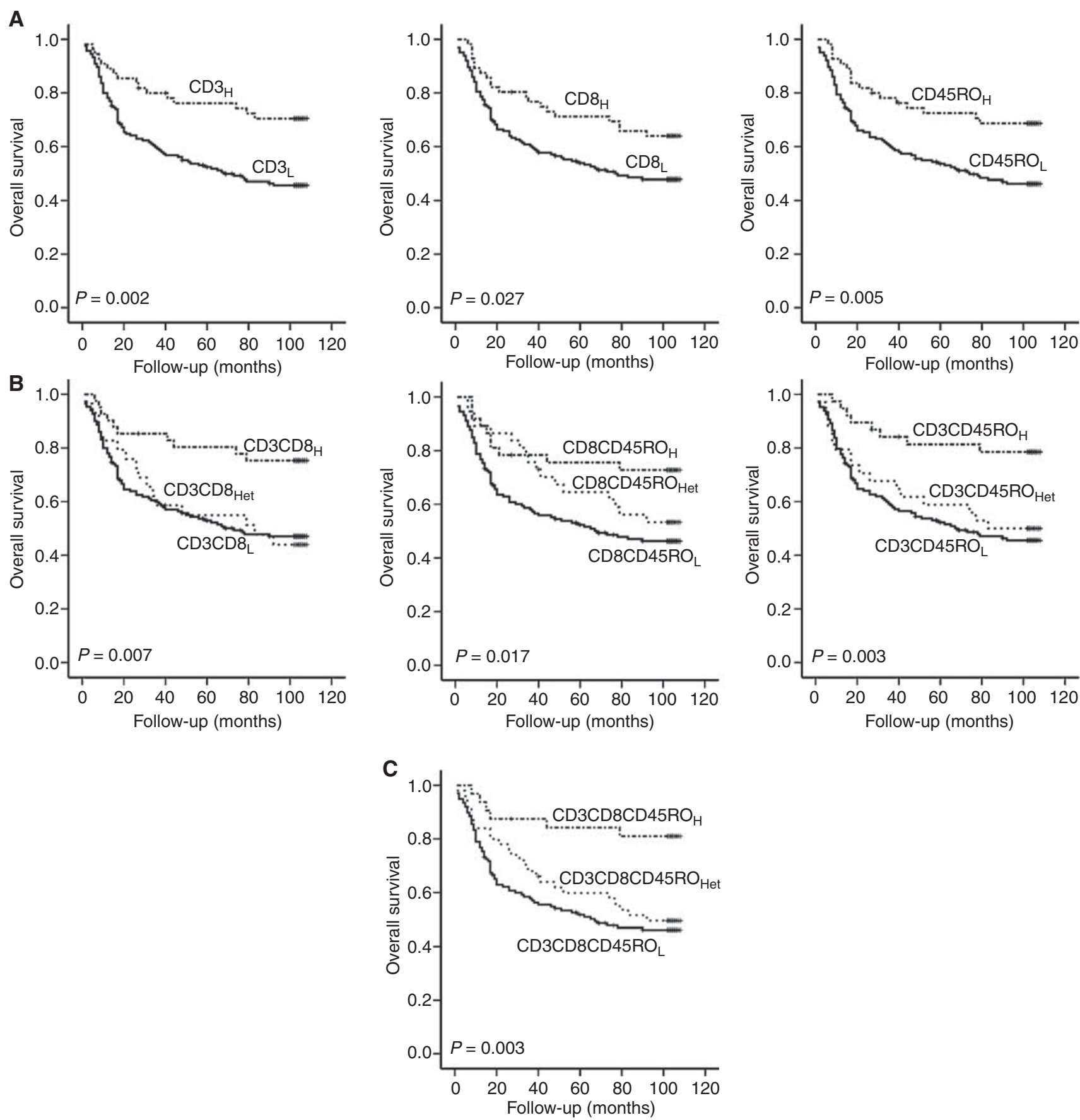

Figure 2 Kaplan-Meier survival plots for the 220 gastric cancer patients as a function of TIL density. (A) Significant differences in overall survival were found between the low- and high-density groups of CD3, CD8, and CD45RO, by the log-rank tests. (B, C) Survival differences were consistently found when analysing with diverse combined TIL variables (refer to Table I).

each stage (Figure 3). This finding suggests that the diversity of clinical outcomes shown by gastric cancer patients with the same TNM stage is due in part to differences in TIL density, which underlines the importance of TIL as a predictor of clinical outcome.

In this study, cases were classified into low or high TIL density groups using mean number or 75 th percentile cutoffs, and the results were consistent regardless of the grouping method used. In addition, analyses using two-fold cross-validation approach strengthened our results, although it failed to show that $\mathrm{CD}^{+}$ TIL density was an independent predictor of overall survival.
Nevertheless, the counting method using image analysis software and the classification system used in this study would be difficult to use clinically. Thus, we suggest that a standard method be devised to measure TIL densities for clinical applications.

Recent studies on colorectal cancer have demonstrated that a high density of $\mathrm{CD} 45 \mathrm{RO}^{+}$TIL is correlated with the absence of lymphovascular invasion and with increased survival (Pages et al, 2005), and further that the densities of $\mathrm{CD}^{+}, \mathrm{CD}^{+}$, and $\mathrm{CD}_{45 \mathrm{RO}^{+}}$TILs are independent prognostic factors (Galon et al, 2006). In a study on ovarian cancer, it was found that the presence of intratumoral $\mathrm{T}$ cells was associated with improved clinical 
Table 5 Univariate and multivariate cox proportional hazards models for the predictors of overall survival (results from mean value cutoffs)

\begin{tabular}{|c|c|c|c|c|c|c|}
\hline \multirow[b]{2}{*}{ Variables } & \multicolumn{3}{|c|}{ Univariate analysis } & \multicolumn{3}{|c|}{ Multivariate analysis $^{\mathbf{a}}$} \\
\hline & HR & $95 \% \mathrm{Cl}$ & $P$-value & HR & $95 \% \mathrm{Cl}$ & $P$-value \\
\hline $\mathrm{CD} 3^{\mathrm{b}}$ & 0.627 & $0.410-0.627$ & 0.031 & 0.813 & $0.523-1.264$ & 0.358 \\
\hline $\mathrm{CD} 8^{\mathrm{b}}$ & 0.583 & $0.358-0.950$ & 0.030 & 0.574 & $0.347-0.949$ & 0.031 \\
\hline$C D 45 R O^{b}$ & 0.530 & $0.331-0.850$ & 0.008 & 0.612 & $0.377-0.995$ & 0.048 \\
\hline $\mathrm{CD} 3 \mathrm{CD}^{\mathrm{C}}$ & 0.522 & $0.303-0.900$ & 0.019 & 0.572 & $0.325-1.010$ & 0.054 \\
\hline CD3CD45RO & 0.441 & $0.252-0.772$ & 0.004 & 0.565 & $0.317-1.009$ & 0.054 \\
\hline CD8CD45RO & 0.416 & $0.221-0.785$ & 0.007 & 0.436 & $0.227-0.838$ & 0.013 \\
\hline $\begin{array}{l}\text { CD3CD8 } \\
\text { CD45RO }\end{array}$ & 0.393 & $0.202-0.766$ & 0.006 & 0.471 & $0.236-0.937$ & 0.032 \\
\hline
\end{tabular}

$\mathrm{Cl}=$ confidence interval; $\mathrm{HR}=$ hazard ratio. The results were according to the density groups of TIL with mean value cutoffs. Univariate and multivariate Cox proportional hazards models were used as statistical methods. ${ }^{\text {TT}}$ Tumour stage (T stage), histologic classification (WHO), presence of lymph node metastasis, and presence of lymphatic invasion which were proved to have a prognostic significance in univariate analysis were adopted as covariates in each multivariate analysis. ${ }^{b}$ High vs low. 'High/high vs low/low. ${ }^{d} H i g h / h i g h / h i g h$ vs low/low/low.

Table 6 Univariate and multivariate cox proportional hazard models for the predictors of overall survival (results from 75th percentile cutoffs)

\begin{tabular}{|c|c|c|c|c|c|c|}
\hline \multirow[b]{2}{*}{ Variables } & \multicolumn{3}{|c|}{ Univariate analysis } & \multicolumn{3}{|c|}{ Multivariate analysis ${ }^{\mathrm{a}}$} \\
\hline & HR & $95 \% \mathrm{Cl}$ & $P$-value & HR & $95 \% \mathrm{Cl}$ & $P$-value \\
\hline $\mathrm{CD}^{\mathrm{b}}$ & 0.446 & $0.261-0.760$ & 0.003 & 0.549 & $0.317-0.951$ & 0.032 \\
\hline CD8 $8^{b}$ & 0.583 & $0.358-0.950$ & 0.030 & 0.574 & $0.347-0.949$ & 0.031 \\
\hline CD45RO ${ }^{b}$ & 0.483 & $0.287-0.813$ & 0.006 & 0.507 & $0.298-0.862$ & 0.012 \\
\hline $\mathrm{CD} 3 \mathrm{CD}^{\mathrm{C}}$ & 0.373 & $0.193-0.721$ & 0.003 & 0.403 & $0.205-0.795$ & 0.009 \\
\hline $\mathrm{CD}^{3} \mathrm{CD} 45 \mathrm{RO}^{\mathrm{c}}$ & 0.305 & $0.147-0.632$ & 0.001 & 0.337 & $0.161-0.708$ & 0.004 \\
\hline $\mathrm{CD}^{8} \mathrm{CD} 45 \mathrm{RO}^{\mathrm{C}}$ & 0.418 & $0.216-0.809$ & 0.010 & 0.413 & $0.211-0.812$ & 0.010 \\
\hline $\begin{array}{l}\text { CD3CD8 } \\
\text { CD45RO }^{d}\end{array}$ & 0.271 & $0.118-0.624$ & 0.002 & 0.282 & $0.121-0.658$ & 0.003 \\
\hline
\end{tabular}

$\mathrm{Cl}=$ confidence interval; $\mathrm{HR}=$ hazard ratio. The results were according to the density groups of TIL with 75th percentile cutoffs. Univariate and multivariate Cox proportional hazards models were used as statistical methods. ${ }^{a}$ Tumour stage (T stage), histologic classification (WHO), presence of lymph node metastasis, and presence of lymphatic invasion which were proved to have prognostic significance in univariate analysis were adopted as covariates in each multivariate analysis. ${ }^{b} \mathrm{High}$ vs low. 'High/high vs low/low. 'High/high/high vs low/low/low.

Table 7 Univariate and multivariate logistic regression models for predictors of regional lymph node metastasis (results from two-fold crossvalidation approach)

\begin{tabular}{|c|c|c|c|c|c|c|}
\hline \multirow[b]{2}{*}{ Variables } & \multicolumn{3}{|c|}{ Univariate analysis } & \multicolumn{3}{|c|}{ Multivariate analysis $^{a}$} \\
\hline & OR & $95 \% \mathrm{Cl}$ & $P$-value & OR & $95 \% \mathrm{Cl}$ & $P$-value \\
\hline $\mathrm{CD}^{\mathrm{b}}$ & 0.42 & $0.211-0.818$ & 0.011 & 0.45 & $0.213-0.935$ & 0.033 \\
\hline $\mathrm{CD} 8^{\mathrm{b}}$ & 0.32 & $0.158-0.630$ & 0.001 & 0.34 & $0.162-0.723$ & 0.005 \\
\hline$C D 45 R^{b}$ & 0.29 & $0.153-0.554$ & $<0.001$ & 0.27 & $0.128-0.554$ & $<0.001$ \\
\hline $\mathrm{CD} 3 \mathrm{CD}^{\mathrm{C}}$ & 0.28 & $0.124-0.614$ & 0.001 & 0.31 & $0.128-0.729$ & 0.003 \\
\hline CD3CD45ROC & 0.26 & $0.123-0.527$ & $<0.001$ & 0.25 & $0.108-0.563$ & $<0.001$ \\
\hline $\mathrm{CD}^{\circ} \mathrm{CD} 45 \mathrm{RO}^{\mathrm{c}}$ & 0.21 & $0.097-0.459$ & 0.001 & 0.20 & $0.085-0.479$ & 0.001 \\
\hline $\begin{array}{l}\text { CD3CD8 } \\
\text { CD45RO }\end{array}$ & 0.20 & $0.083-0.463$ & $<0.00$ & 0.20 & $0.077-0.518$ & $<0.001$ \\
\hline
\end{tabular}

$\mathrm{Cl}=$ confidence interval; $\mathrm{OR}=$ odds ratio. Univariate and multivariate logistic regression models were used as statistical methods. ${ }^{a}$ Tumour invasion ( $T$ stage) and presence of lymphatic invasion were adopted as covariates in each multivariate

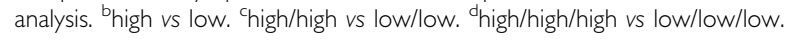

outcome (Zhang et al, 2003). Previous reports also show that hepatocellular and urothelial carcinoma patients with high numbers of $\mathrm{CD}^{+}$TIL within tumour tissues have better
Table 8 Univariate and multivariate cox proportional hazards models for the predictors of overall survival (results from two-fold cross-validation approach)

\begin{tabular}{|c|c|c|c|c|c|c|}
\hline \multirow[b]{2}{*}{ Variables } & \multicolumn{3}{|c|}{ Univariate analysis } & \multicolumn{3}{|c|}{ Multivariate analysis $^{a}$} \\
\hline & HR & $95 \% \mathrm{Cl}$ & $P$-value & HR & $95 \% \mathrm{Cl}$ & $P$-value \\
\hline$C D 3^{b}$ & 0.57 & $0.343-0.935$ & 0.026 & 0.67 & $0.404-1.123$ & 0.130 \\
\hline CD $8^{b}$ & 0.59 & $0.374-0.938$ & 0.026 & 0.64 & $0.408-1.003$ & 0.052 \\
\hline CD45RO ${ }^{b}$ & 0.30 & $0.151-0.594$ & 0.001 & 0.42 & $0.209-0.843$ & 0.015 \\
\hline $\mathrm{CD} 3 \mathrm{CD} 8^{\mathrm{c}}$ & 0.49 & $0.288-0.837$ & 0.009 & 0.56 & $0.324-0.964$ & 0.037 \\
\hline CD3CD45RO & 0.34 & $0.162-0.691$ & 0.003 & 0.44 & $0.211-0.923$ & 0.030 \\
\hline $\mathrm{CD}^{8 C D} 45 \mathrm{RO}^{\mathrm{C}}$ & 0.28 & $0.134-0.592$ & 0.001 & 0.36 & $0.170-0.768$ & 0.008 \\
\hline $\begin{array}{l}\text { CD3CD8 } \\
\text { CD45RO }\end{array}$ & 0.31 & $0.148-0.656$ & 0.002 & 0.39 & $0.185-0.836$ & 0.015 \\
\hline
\end{tabular}

$\mathrm{Cl}=$ confidence interval; $\mathrm{HR}=$ hazard ratio. Univariate and multivariate Cox proportional hazard models were used as statistical methods. ${ }^{a}$ Tumour stage ( $T$ stage), histologic classification $(\mathrm{WHO})$, presence of lymph node metastasis, and presence of lymphatic invasion which were proved to have prognostic significance in univariate analysis were adopted as covariates in each multivariate analysis. bhigh vs low. " high/high vs low/low. 'high/high/high vs low/low/low.

survival (Gao et al, 2007; Sharma et al, 2007). In terms of lymph node metastasis, Taylor et al (2007) reported that brisk TIL infiltration in tumour predicts sentinel lymph node metastasis in melanoma patients, and Piersma et al (2007) demonstrated that a high number of intraepithelial $\mathrm{CD}^{+}$TIL is associated with the absence of lymph node metastasis in uterine cervical cancer.

However, the prognostic role of tumour-infiltrating immune cells in patients of gastric cancer is largely unknown. Only a few reports have been issued on the association between tumourinfiltrating immune cells and the clinical outcome in gastric cancer; Ishigami et al (2000) reported that patients showing a high level of natural killer cell infiltration in tumour tissues have a better prognosis, and Maehara et al (1997) showed that a high density of dendritic cell infiltration is associated with the absence of lymph node metastasis. Ichihara et al (2003) reported that the population of regulatory $\mathrm{T}$ cells among the TILs of patients with advanced disease $(n=8)$ is significantly higher than that among the TILs of patients with early disease $(n=7)$. On the other hand, Fukuda et al (2002) found no significant difference in survival between patients with marked or slight TIL infiltration, which does not agree with our findings. However, they detected TILs by UCLH-1 immunostaining in 129 gastric cancer patients, classified cases into groups with marked or slight TIL infiltration, and did not determine TIL numbers. In this study of a large series of gastric cancers, we counted the number of tumour-infiltrating total $\mathrm{T}$ cells, cytotoxic $\mathrm{T}$ cells, memory $\mathrm{T}$ cells, and $\mathrm{B}$ cells using an image analyser, and for the first time demonstrated the prognostic importance of TIL in gastric cancer.

T-cell mediated adaptive immunity is considered to play a major role in anti-tumour immunity. In mouse models, it has been demonstrated that adaptive immunity prevents the development of tumours and inhibit tumour progression (Dunn et al, 2004). Consistent with these results, our findings show that high densities of immune cells related to adaptive immunity, that is, total T cells, cytotoxic $\mathrm{T}$ cells, and memory $\mathrm{T}$ cells, are associated with favourable survival, and indicate that adaptive immunity plays a role in the prevention of tumour progression. On the other hand, tumour-infiltrating B cells are found not to have impact on patient survival in this study. Previous reports have concluded that B lymphocytes and humoral immunity are associated with tumour progression (de Visser et al, 2006; Sabbatini and Odunsi, 2007), which is not contradicted by our findings.

According to our results, TIL density is correlated with the presence of lymph node metastasis but not with depth of tumour 

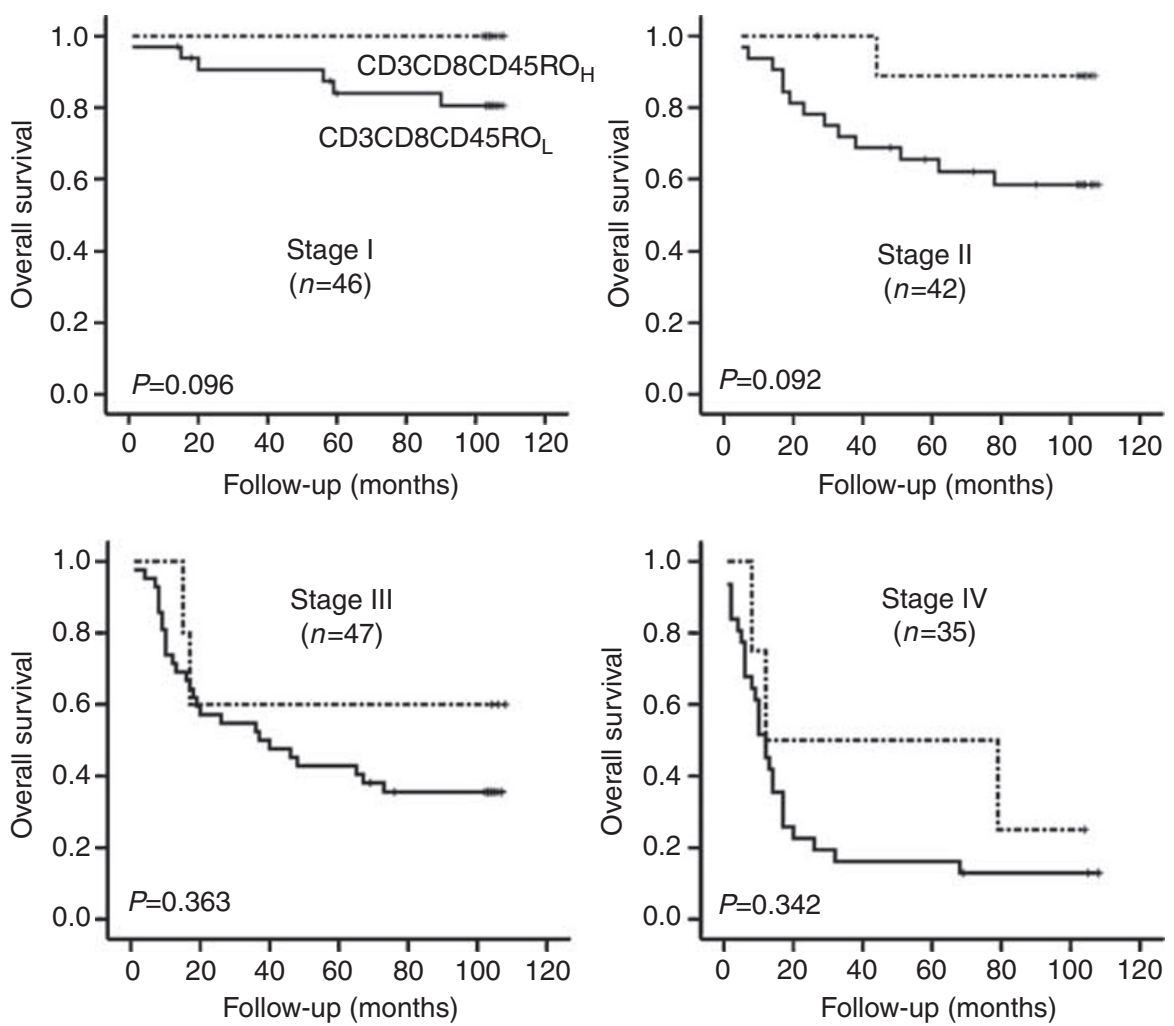

Figure 3 Kaplan-Meier survival analysis of TIL densities at different stages of the TNM classification (log-rank tests). High TIL density tended to be associated with longer overall survival within a given TNM stage. The results were from 75th percentile cutoffs.

invasion. On the basis of this finding, we suspect that the prognostic role of TIL is mainly contributed to decreased metastatic potential. We suggest the following possible mechanisms how TIL act to reduce metastatic potential. First, clones with metastatic potential usually contain larger amounts of aberrantly expressed proteins, including proteins that contribute to metastasis, which may act as tumour-associated antigens. As a result, these clones are more likely to be destroyed by in situ immune reactions. Second, a high density of TIL means a healthy immune system, and therefore, immune reaction occurring in lymph node may also exert a proper function against tumour cells that have drained into lymph nodes in patients with high TIL densities. Third, tumour burden of metastatic foci in lymph node is less bulky than those of primary foci, and thus, metastatic foci are more likely to be susceptible to complete destruction by immune reaction.

In this study, we evaluated TIL distributions immunohistochemically, and although the majority of previous reports have also used this method, it has some limitations. First, the results obtained are dependent on the antibodies used. Second, various components of immune system such as interferon- $\gamma$ (IFN- $\gamma$ ), IFN- $\gamma$ receptor, transcription factor signal transducers and activators of transcription 1 (STAT1), perforin, and interleukins which can affect in situ immune reaction against tumour, and therefore, impact on patients' survival were not considered. Thus, additional studies are required to elucidate the expressional status of immune-related genes in tumour tissues.

\section{REFERENCES}

Chen CN, Lin JJ, Chen JJ, Lee PH, Yang CY, Kuo ML, Chang KJ, Hsieh FJ (2005) Gene expression profile predicts patient survival of gastric cancer after surgical resection. J Clin Oncol 23: 7286-7295
Significant advances have been made in the field of cancer immunotherapy over the last decade, and many nonrandomised, phase II, immune-targeted trials have shown that immunotherapy can confer survival benefits, although these benefits were not confirmed in phase III trials (Rosenberg et al, 2004; Sabbatini and Odunsi, 2007). In gastric cancer, immunotherapy has not been shown to confer a survival benefit, although a clinical trial on postoperative adjuvant immunochemotherapy is currently in progress in Japan (Ueda et al, 2006). It is hoped that the observations made during this study will provide crucial information concerning the design of effective immunotherapies, and aid the identification of patients suitable for immunotherapy.

In conclusion, we elucidated the prognostic implications of the density of various types of TIL in gastric cancer. Moreover, our results suggest that adaptive immunity does act to prevent tumour progression. We believe that our findings can help predict clinical outcome and define patient subgroups with an unfavourable prognosis in gastric cancer. Furthermore, our observation will be useful for selecting patients that are more likely to benefit from the promising adjuvant immunotherapy.

\section{ACKNOWLEDGEMENTS}

This work was supported by FG06-11-03 of 21C Frontier Functional Human Genome Project from Ministry of Education, Science and Technology of Korea. 
Coombes RC, Schein PS, Chilvers CE, Wils J, Beretta G, Bliss JM, Rutten A, Amadori D, Cortes-Funes H, Villar-Grimalt A (1990) A randomized trial comparing adjuvant fluorouracil, doxorubicin, and mitomycin with no treatment in operable gastric cancer. International Collaborative Cancer Group. J Clin Oncol 8: $1362-1369$

de Visser KE, Eichten A, Coussens LM (2006) Paradoxical roles of the immune system during cancer development. Nat Rev Cancer 6: 24-37

Dunn GP, Old LJ, Schreiber RD (2004) The three Es of cancer immunoediting. Annu Rev Immunol 22: 329-360

Engstrom PF, Lavin PT, Douglass Jr HO, Brunner KW (1985) Postoperative adjuvant 5-fluorouracil plus methyl-CCNU therapy for gastric cancer patients. Eastern Cooperative Oncology Group Study (EST 3275). Cancer 55: $1868-1873$

Fenoglio-Preiser C, Carneiro F, Correa P, Guilford P, Lambert R, Megraud F, Munoz N, Powell SM, Rugge M, Sasako M, Stolte M, Watanabe H (2000) Gastric carcinoma, In World Health Organization Classification of Tumors; Pathology and Genetics of Tumors of the Digestive System, Hamilton SR, Aaltonen LA (eds), pp 37-52. IARC Press: Lyon, France

Fukuda K, Tsujitani S, Maeta Y, Yamaguchi K, Ikeguchi M, Kaibara N (2002) The expression of RCAS1 and tumor infiltrating lymphocytes in patients with T3 gastric carcinoma. Gastric Cancer 5: 220-227

Galon J, Costes A, Sanchez-Cabo F, Kirilovsky A, Mlecnik B, Lagorce-Pages C, Tosolini M, Camus M, Berger A, Wind P, Zinzindohoue F, Bruneval P, Cugnenc PH, Trajanoski Z, Fridman WH, Pages F (2006) Type, density, and location of immune cells within human colorectal tumors predict clinical outcome. Science 313: 1960-1964

Gao Q, Qiu SJ, Fan J, Zhou J, Wang XY, Xiao YS, Xu Y, Li YW, Tang ZY (2007) Intratumoral balance of regulatory and cytotoxic $T$ cells is associated with prognosis of hepatocellular carcinoma after resection. J Clin Oncol 25: 2586-2593

Goseki N, Takizawa T, Koike M (1992) Differences in the mode of the extension of gastric cancer classified by histological type: new histological classification of gastric carcinoma. Gut 33: 606-612

Hippo Y, Taniguchi H, Tsutsumi S, Machida N, Chong JM, Fukayama M, Kodama T, Aburatani H (2002) Global gene expression analysis of gastric cancer by oligonucleotide microarrays. Cancer Res 62: 233-240

Ichihara F, Kono K, Takahashi A, Kawaida H, Sugai H, Fujii H (2003) Increased populations of regulatory $\mathrm{T}$ cells in peripheral blood and tumor-infiltrating lymphocytes in patients with gastric and esophageal cancers. Clin Cancer Res 9: 4404-4408

Ishigami S, Natsugoe S, Tokuda K, Nakajo A, Che X, Iwashige H, Aridome K, Hokita S, Aikou T (2000) Prognostic value of intratumoral natural killer cells in gastric carcinoma. Cancer 88: 577-583

Lauren P (1965) The two histological main types of gastric carcinoma: diffuse and so-called intestinal-type carcinoma. an attempt at a histoclinical classification. Acta Pathol Microbiol Scand 64: 31-49
Lee HS, Lee HK, Kim HS, Yang HK, Kim YI, Kim WH (2001) MUC1, MUC2, MUC5AC, and MUC6 expressions in gastric carcinomas: their roles as prognostic indicators. Cancer 92: 1427- 1434

Lewin KJ, Appleman HD (1996) Carcinoma of the stomach. In Atlas of Tumor Pathology; Tumors of the Esophagus and Stomach, Rosai J (ed), pp 245 - 330. Armed Forces Institute of Pathology: Washington DC, WA Maehara Y, Tomisaki S, Oda S, Kakeji Y, Tsujitani S, Ichiyoshi Y, Akazawa K, Sugimachi K (1997) Lymph node metastasis and relation to tumor growth potential and local immune response in advanced gastric cancer. Int J Cancer 74: 224-228

Mazumdar M, Smith A, Bacik J (2003) Methods for categorizing a prognostic variable in a multivariable setting. Stat Med 28: 559-571

Ming SC (1977) Gastric carcinoma. A pathobiological classification. Cancer 39: $2475-2485$

Pages F, Berger A, Camus M, Sanchez-Cabo F, Costes A, Molidor R, Mlecnik B, Kirilovsky A, Nilsson M, Damotte D, Meatchi T, Bruneval P, Cugnenc PH, Trajanoski Z, Fridman WH, Galon J (2005) Effector memory $\mathrm{T}$ cells, early metastasis, and survival in colorectal cancer. $N$ Engl J Med 353: 2654-2666

Parkin DM, Bray F, Ferlay J, Pisani P (2005) Global cancer statistics, 2002. CA Cancer J Clin 55: 74-108

Piersma SJ, Jordanova ES, van Poelgeest MI, Kwappenberg KM, van der Hulst JM, Drijfhout JW, Melief CJ, Kenter GG, Fleuren GJ, Offringa R, van der Burg SH (2007) High number of intraepithelial CD8+ tumorinfiltrating lymphocytes is associated with the absence of lymph node metastases in patients with large early-stage cervical cancer. Cancer Res 67: $354-361$

Rosenberg SA, Yang JC, Restifo NP (2004) Cancer immunotherapy: moving beyond current vaccines. Nat Med 10: 909-915

Sabbatini P, Odunsi K (2007) Immunologic approaches to ovarian cancer treatment. J Clin Oncol 25: 2884-2893

Sharma P, Shen Y, Wen S, Yamada S, Jungbluth AA, Gnjatic S, Bajorin DF, Reuter VE, Herr H, Old LJ, Sato E (2007) CD8 tumor-infiltrating lymphocytes are predictive of survival in muscle-invasive urothelial carcinoma. Proc Natl Acad Sci USA 104: 3967-3972

Taylor RC, Patel A, Panageas KS, Busam KJ, Brady MS (2007) Tumorinfiltrating lymphocytes predict sentinel lymph node positivity in patients with cutaneous melanoma. J Clin Oncol 25: 869-875

Ueda Y, Fujimura T, Kinami S, Hirono Y, Yamaguchi A, Naitoh H, Tani T, Kaji M, Yamagishi H, Miwa K (2006) A randomized phase III trial of postoperative adjuvant therapy with S-1 alone versus S-1 plus PSK for stage II/IIIA gastric cancer: Hokuriku-Kinki Immunochemo-Therapy Study Group-Gastric Cancer (HKIT-GC). Jpn J Clin Oncol 36: 519-522

Zhang L, Conejo-Garcia JR, Katsaros D, Gimotty PA, Massobrio M, Regnani G, Makrigiannakis A, Gray H, Schlienger K, Liebman MN, Rubin SC, Coukos G (2003) Intratumoral $\mathrm{T}$ cells, recurrence, and survival in epithelial ovarian cancer. $N$ Engl J Med 348: 203-213 